Simple suggestions such as the improvement of discharge letters to general practitioners can be pursued by every consultant and offer an ideal of setting standards for junior doctors.

\section{Computer systems to help medical audit}

The two systems the Working Group are considering are (i) The CRISP system set up by Dr P. Rohde, and (ii) the system by Ed Sein set up in Newcastle and also in Leicester.

\section{Recommended Reading}

1. Medical Audit-Hospital Handbook, King's Fund, edited by Charles Shaw.

2. Nicol, A. R. (1989) Performance indicators in child and adolescent psychiatry. Psychiatric Bulletin, 13, 94-97.

3. Guy Edwards, J., NunN, C. M. H. \& Ricketts, B. S. (1987) Three years of medical audit in a psychiatric unit. Bulletin of the Royal College of Psychiatrists, 11, 154-155.

4. Brewin, C. R., Wing, J. R., Mangen, S. P., Brugha, T.S.\& MACCARTHY, B. (1987)Principles and practice of measuring needs in the long-term mentally ill: the MRC needs for care assessment. Psychological Medicine, 17, 971-981.

5. Medical Audit:-A report of the Royal College of Physicians published in March 1989.

6. Royal College of Psychiatrists Research Committee Report from Pilot Survey on the Use of Depot Neuroleptics (not yet for publication).
7. Mrtchell, M. \& Foukes, F. (1985) Audit reviewed: does feed-back of performance change clinical behaviour? Journal of the Royal College of Physicians, 19, 251-254.

8. COCHRANE, A. L. (1971) Effectiveness and Efficiency: Random Reflection on Health Services, Nuffield Provincial Trust.

9. Section for the Psychiatry of Old Age: report of Working Group on Performance Indicators.

10. Health Service Indicators Group: A Report on Körner Indicators, December 1988.

11. Denford, T., Schachter, J., Temple, N., Kind, P. \& ROsser, R. (1983) Selection and outcome in in-patient psychotherapy. British Journal of Medical Psychology. 56, 225-243.

12. Rosser, R. (1988) A health index and output measures. In Quality of Life Measurements (eds. S. Walker and R. Rosser). MTP Press.

13. HIRSCH, S. R. (1988) Psychiatric Beds and Resources: Factors Influencing Bed Use and Service Planning. London: Gaskell (Royal College of Psychiatrists).

\section{Membership of the Working Party:}

Dr Ann Gath - Registrar and Convenor

Dr Fiona Caldicott - Sub-Dean

Dr James Higgins - Sub-Dean

Dr Norman Kaye-representing the Public Policy Committee

Professor John Wing-Research Director (from September, 1989)

Professor Michael Gelder-Chairman, Research Committee.

Approved by Council June 1989

\title{
Training in the psychiatry of old age
}

While the number of patients admitted to psychiatric hospitals aged $18-65$ has fallen slightly, the number aged $65+$ (and especially $75+$ ) has risen considerably, so that they constitute a third of all psychiatric admissions.

Many general psychiatrists will be treating elderly patients and will need to acquire the skills and methods of the psychiatry of old age. This should be obtained, wherever possible, in a unit with a consultant specialising in the subject.

Experience in the psychiatry of old age will be recognised for Part I of the MRCPsych, provided that the following conditions are met:

(a) there is wide variety of types of patients and clinical conditions, including those with functional disorders, treated and assessed in a variety of settings

(b) teaching focuses on general principles and techniques of general psychiatry as well as on the particular aspects of psychiatry in old age.

The Court of Electors has made it clear that a candidate in the Part I of the Examination may be expected to examine a patient with an organic mental state. Training in old age psychiatry may be particularly useful for this.

Approved by the Court of Electors 19 June 1989 